\title{
Investors in People and Business Excellence in the United Arab Emirates Part 2: From BE to IIP — a Case Study
}

\author{
Alaa Garad, Investors in People, United Arab Emirates \\ Fiona Martis, Independent Management Consultant, \\ United Arab Emirates
}

\begin{abstract}
Interesting developments are taking place in the United Arab Emirates in relation to national and organizational HRD policy and practice. These focus upon an approach which seeks to build upon and ultimately integrate standards drawn from the models of Business Excellence (BE) and Investors in People (IIP). In this the second of a two-part article a case study is presented which illustrates the combined benefits of the two standards. The article draws out the practice initiatives and achievements taken by the case organization - a large hotel in Abu Dhabi — in developing from BE to IIP. An integrated model offers national and organizational HRD a challenging but exciting prospect. Potential benefits in seeking to apply such an organization development approach go beyond a mere aggregation of IIP and BE. A key implication is the development of an understanding of how the two models can work together.
\end{abstract}

Key Words: business excellence, EFQM, IIP, HRD, organization development, hospitality, UAE

\section{Introduction}

This article attempts to illustrate how working with the Business Excellence Model (BEM) and Investors in People (IIP) can help organizations to succeed in fulfilling their mission. Key links between BEM and IIP were highlighted and discussed in part one of this article (Garad, 2016). The aim of part two is to take stock of the practices that have been employed in a case study from the United Arab Emirates (UAE) and which illustrate the combined benefits of the two international standards i.e. IIP and BEM.

A single case study organization, the Millennium Corniche Hotel in Abu Dhabi, United Arab Emirates, is the subject of this research. A qualitative approach was adopted to investigate and understand the links between both models and draw out the practice initiatives and achievements taken by the hotel in developing from 'business excellence' to IIP. Several methods were used in data collection including participant observer methods, semi-structured interviews, focus groups and document review.

By using the IIP framework on the back of the Business Excellence (BE) model, the case study organization experienced positive impact on their people development practices and witnessed benefits such as improved organization culture, increased customer satisfaction, employee engagement and savings on cost in recruitment and other areas. The article first discusses the development process from BE to IIP. It then explores one case study in detail before drawing 
conclusions about the relationship between and benefits of BE and IIP for organizational and national HRD.

\section{BE and IIP: Recap}

The concept of Business Excellence (BE) has its origins in the quality movement in post-WWII Japan. Over the years, this movement gave rise to several approaches and frameworks that organizations could adopt with a view to enhance their quality and performance. One such widely-used BE framework is the European Foundation for Quality Management (EFQM), that defines BE as:

Outstanding practices in managing the organization and achieving results based on a set of fundamental concepts which will include: result orientation, customer focus, leadership, and constancy of purpose, management by processes and facts, involvement of people, continuous improvement and innovation, mutually beneficial partnership, and corporate social responsibility (EFQM, 2003: 33).

The UAE has embraced BE as a means to foster its competitiveness in an international arena by focusing on a culture of quality and excellence.

IIP is a holistic framework for people management established by the UK Commission for Employment and Skills in the early 1990s that defines what it takes to lead, support and effectively manage people for sustainable results. The IIP Standard has been reviewed and updated regularly to respond to and reflect the changes in management best practices. Organizations that adopt the Standard may elect to either apply for accreditation or not. If they choose to apply for formal accreditation by IIP, they are then subject to assessments and, if successful, will be recognized at one of the following Accreditation levels: 'Accredited', 'Silver', 'Gold' or 'Platinum'.

Organizations in the UAE are using IIP to progress beyond BE and enhance their learning and performance capabilities.

\section{The Journey in Practice: The Millennium Corniche Hotel, Abu Dhabi}

\section{Company background}

The Millennium Corniche Hotel in Abu Dhabi is a five-star property that opened its doors in the Emirate in the year 2002. It is part of the Millennium Hotels and Resorts, an international chain of hotels that was founded in 1989 by its Chairman, Kwek Leng Beng, of Singapore's Hong Leong Group. The Millennium Hotels and Resorts currently operate 63 properties globally in 18 countries. In the UAE, they manage six properties spread across three Emirates. The Millennium Corniche Hotel has a staff strength of 200 employees and is one of two Millennium properties in Abu Dhabi. It is the first of the Group's properties in the Middle East to apply for IIP accreditation.

\section{From BE to IIP}

In 2007, the hotel achieved the Sheikh Khalifa Excellence Award (SKEA) which is based on EFQM's nine criteria. This award was the beginning of the culture change and journey to excellence that was later complemented by embarking on the strategic implementation of 
the IIP Standard. When the hotel achieved the SKEA the management realized that the award model is very comprehensive and yet there was still a lot to be done to accomplish the hotel's objectives and become one of the leading organizations in Abu Dhabi. Indeed, the BEM/SKEA assessors had documented a need for further engagement of people, more financial and nonfinancial recognition, linking training and L\&D activities to the hotel's mission and objectives, further involvement of senior management with people, and measuring the return on investment in training.

In subsequent years, competition within the hospitality sector intensified. Plans for new hotels in Abu Dhabi brought the realization that the hotel would have to contend with luxury brands in an increasingly fierce market. They acknowledged the fact that further changes would need to be made within the hotel to stay competitive and that the changes begun with BE needed progression and enhancement The potential of IIP was introduced to the hotel. A change in senior management in 2014 provided a stimulus for action. A new General Manager (GM) was appointed, who had personally experienced the success of IIP in the UK. Aware of the potential benefits of the Investors in People framework and the links between IIP and Business Excellence he believed that focusing on people development and continuous learning could lead to a positive shift in the organizational culture and thus further propel the hotel's journey to excellence. A priority for the GM was to bring in operational excellence in people's daily practice as he believed that "it is all about people". He took the position that whilst the SKEA model gave the holistic coverage of all aspect of organizational excellence, the particular context of the hotel necessitated more focus on people considering the nature of business and the competition it was facing. Areas of the operation where it was felt required further development were people engagement and ensuring ownership and alignment of learning and development activities to the hotel's mission and strategic objectives.

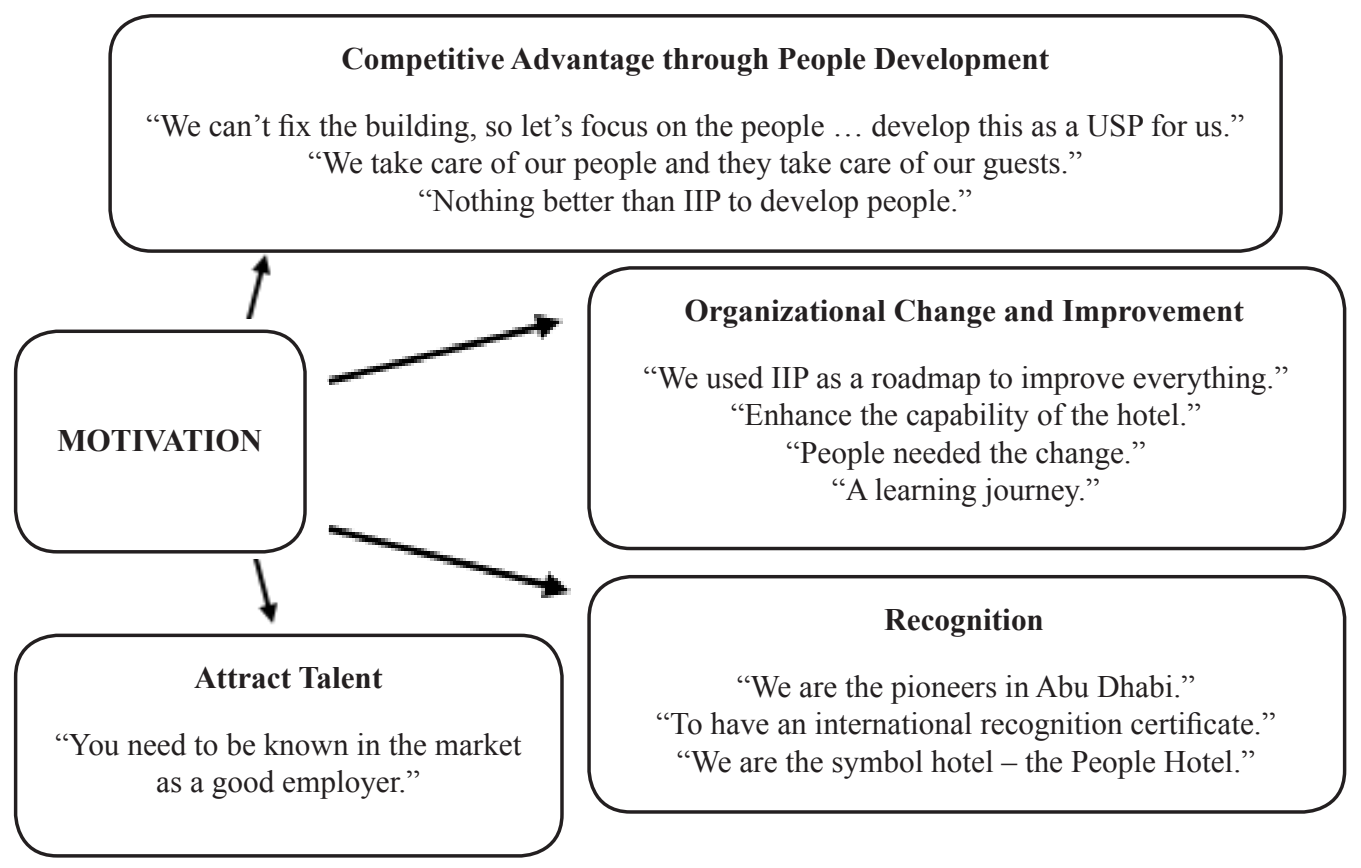

Figure 1: Motivation Factors for Implementing IIP 
The GM approached Investors in People UAE to share and explore the adoption of IIP in line with the SKEA model. Agreement to progress the hotel towards IIP accreditation was taken in January 2015. In sum, the rationale was: 1) to gain competitive advantage through people development, 2) to facilitate organizational change and improvement, 3) to cultivate a culture of recognition and reward and 4) to help attract talent — as illustrated in Figure 1.

\section{Implementing IIP}

The GM formed a cross functional team and started the journey of Investors in People. The beginning was an awareness session conducted by the first author of this article and attended by all senior management and middle management teams at the hotel to demonstrate and highlight the links between both models and answer the enquiries of the management.

After this first review by an IIP specialist, the GM set up an IIP project team comprising the HR Director, the Training Manager and the Food and Beverage (F\&B) Director, with the GM personally taking charge of the implementation. The implementation of the IIP framework at the hotel commenced with laying the groundwork - formulating the hotel's Vision and Mission. The interview data revealed that before engaging with IIP, the hotel did not have either. They were "waiting for the corporate office" to provide them with this. Once the decision was made to adopt the IIP Standard and subsequent to the first report from the visiting IIP specialist, this was quickly rectified. Thereafter, job descriptions and objectives were reviewed and rewritten to align with these.

In late January 2015, the newly minted Vision and Mission was launched to the whole organization through a "kick-off session" led by the GM and various department heads. All employees were invited to this session and $100 \%$ attendance was achieved. This would be the first time that all hotel employees (or "colleagues" as they are referred to at the hotel) would meet together. It was explained to employees how their job roles could add value to the hotel and help the organization meet its goals.

This session was also used to introduce the IIP Standard to the hotel employees and inform them that the hotel would be applying for the accreditation. The session was closed with the employees being invited to place their handprints in colourful paint on several large canvases. This would serve as a visual representation of their commitment to the hotel's Vision, Mission and Values. A video of the session is available on YouTube at the following link: https://www.youtube.com/ watch?v=QzNF0iXqu9I The canvases are prominently displayed in the hotel's staff cafeteria which is frequented by the employees at least once during the working day.

The project team then started implementing the culture shift by revamping HR practices, building employee engagement within the hotel and improving communication. Using the indicators of the IIP Standard (see also Figure 2) as a guide, changes were made across the hotel. These changes included developing a country-specific company Mission \& Vision statement, redefining job roles, reviewing performance management and succession planning policies, empowering employees to take decisions and actively soliciting employee feedback to co-create a participative organizational culture.

In the twelve months of implementation, however, the hotel did face difficulties and challenges. One such was regarding communication to the whole organization. While the initial kick-off session laid the foundation, and brought about awareness of IIP, the messaging was best received by the management and supervisory level employees. This fact was brought to light during the 
IIP assessment visit where most of the employees who were interviewed by the IIP assessor belonged to the non-management strata. The IIP assessors found that while management understood what IIP was about and why it was being adopted, the bulk of the workforce (most of whom are customer-facing) did not! They either could not articulate or did not understand what the adoption of IIP essentially meant for them and their jobs.

Hence, in order to target every employee - from the housekeeping colleagues to the wait staff and kitchen staff - communication was reinforced via more personal, unit-wise discussions by members of the IIP project team working alongside the department heads. During these sessions employees were told once again (and in some cases, in their native languages) what the hotel's vision, mission and values are; what IIP is; how their job roles are linked to the hotel's vision and guest satisfaction; how they are empowered to make decisions; what training and development options are available to them and what they are expected to do in their jobs. While this was acknowledged as being a massive undertaking, it was viewed as critical by the hotel to achieve the cultural shift.

A second hurdle the hotel faced was quantifying and explaining the value that could be achieved from the investment made in the training and development activities. The IIP assessor requested that the hotel attempt to evidence these gains so that the information could be used by the management for forward business planning. This information could also help the hotel home in on any changes that may be required to be made to their people management and development activities. Overcoming this challenge was an iterative process for the project team who themselves went through a learning journey to determine what items could and should be measured. Once that understanding was gained, they were able to successfully produce the data and track progress.

It is useful also to note that the implementation slowed down in the middle of the year since the hotel's F\&B Director and Training Manager both moved to other Millennium properties to take on new roles. The implementation was not abandoned, however, and the communication channels were kept open. A new Training Manager and F\&B Director were brought on board in August 2015 and the implementation picked up pace again. The IIP accreditation assessment was due in September 2015 and while this assessment noted marked positive improvements to the hotel's practices from January, more changes were deemed necessary if the hotel was to gain accreditation. The hotel was allowed three months to address comments from the IIP assessor and re-submit their application. In December 2015 the progress was reassessed by IIP and by January 2016 the hotel was awarded the IIP Silver Accreditation. In June 2016, at the Investors in People Awards ceremony held in the UK, the hotel picked up the top accolade in the "Best Newcomer (International)" category.

As suggested by earlier work and research on the practice of IIP, the enablers and challenges that the hotel faced during the implementation phase are not uncommon. Berry and Grieves (2003) noted that support from senior management and the creation of a dedicated project team or at least an in-house IIP champion are important to successful implementation. Further, Smith (2000) commented that a cornerstone in the change of corporate culture was workforce involvement and engagement whereby employees become responsible and are more in control of their own learning and development - along with receiving management support. Similarly, the 
sorts of difficulties the hotel encountered are also reported in previous studies. Hill and Stewart (1999) and Smith et al (2002), for example, both highlighted the time taken for implementation and the extensive, ongoing communication required as significant barriers. Collins and Smith (2004) cautioned that some firms found the language used by IIP was vague and was open to interpretation. In this case study, the hotel found that it took a few attempts on their part to understand what kind of quantifiable measures were required to satisfy the IIP accreditation standards.

\section{LEADING}

\section{Leading and Inspiring People}

- Job roles aligned with the hotel's new vision, mission and values.

- Quarterly events where the senior management team serves all employees.

- Monthly town hall meetings.

\section{Living the} Organization's Values

- New Orientation Programme for all employees

- Corporate wellness programme instituted
Empowering and Involving People

- Empowerment policy created.

- Employee involvement, feedback and engagement proactively sought.

- Regular social activities.

- Revenue and performance data and forward business plans circulated.

- Employee-driven monthly newsletters.

\section{SUPPORTING}

\section{Managing Performance}

- Performance management system and policies revamped.

- Performance appraisal forms changed to incorporate relevant competencies and continuous improvement.
Recognizing and Rewarding High Performance

- Employee recognition improved.

- Social Media Awards instituted.

- Employee accomplishments prominently displayed.
Structuring Work

- Five-day working week instituted.

\section{IMPROVING}

\section{Building Capacity}

- Comprehensive training plan created.

- Focus on managerial developing.

- Cross-training sessions.

- In-house library set up.
Delivering Continuous Improvement

- Specialist trainers contracted to improve Front Office capabilities.

\section{Creating} Sustainable Success

- Succession planning system revisited.

Figure 2: Initiatives Undertaken for IIP Implementation 


\section{Impact and Assessment}

\section{Changes introduced}

From the data gathered through the interviews with the management team, some of the initiatives undertaken by the hotel to improve organizational performance along their IIP-accreditation journey are presented below. For ease of reference, they are first diagrammatically represented under the nine Indicators of the IIP Framework. Illustrative information on each of the initiatives is then provided in Tables $1-4$.

\section{Workforce Development - Changes in HR Practices}

- Job roles were clearly defined and goals revisited to better align with the hotel's new vision, mission and values.

- The performance management system was revamped to ensure a mid-year and an annual review for every employee, in addition to a 6-month probationary review for new joiners. The performance appraisal forms were changed to incorporate competencies such as Team spirit, Innovation and Drive. Continuous improvement was strongly promoted.

- Performance reviews are now conducted by an employee's direct supervisor and not the department head who may or may not have frequent contact with the employee.

- The approach to disciplinary action was completely changed. Before IIP, department heads could issue warning letters at the first instance. Warning letters are now only issued in extreme cases. Instead, the recommended course of action is to counsel the employee first and determine how the hotel can help them do their job better and avoid such a situation in the future.

- A service recovery and empowerment policy was drawn up to enable employees to make quicker decisions and take responsibility for guest satisfaction.

- The succession planning system was revisited. An existing plan was in place but was not effectively being used. The new plan factored in employees' performance and training records and any new vacancies were encouraged to be filled internally using the data from the new succession plan.

- A five-day working week was instituted across most departments. Before IIP, this was only prevalent in the administrative offices and with the senior management team. After IIP implementation, all employees are entitled to two days off during the week. During peak seasons, the days off are sometimes carried forward to alternate weeks but are not lost.

- The employee-of-the-month recognition scheme, previously determined by department heads, now sees the employee of the month selected by the employees themselves via a voting system. The new system opens up this popular recognition programme to employees from all areas of the hotel.

- A Supervisor of the Month award has also been adopted giving employees the opportunity to recognize line managers and supervisors who have contributed to their growth and development.

- Social Media Awards are given to those employees who receive the most number of compliments on the hotel's social media sites.

Table 1: Workforce Development - Changes in HR Practices 


\section{Workforce Development — Learning and Development}

- All employees, new and old (including heads of departments) were "re-oriented" or, simply put, they attended the hotel's new orientation programme.

- A new training plan was drawn up and circulated to every department. Managers nominate employees for essential training courses but also encourage employees to sign up for other training courses (even those not directly related to their daily jobs) and take charge of their own learning and development.

- Focus on developing managerial skills:

- All people managers were trained on how to manage performance, conduct performance reviews and appraisals and target the correct type of training for their teams.

- All people managers are asked to attend a Train-the-Trainer programme.

- Leadership development courses are provided.

- On-The-Job training for managers was introduced.

- A specialist training company was contracted to assist the Front Office with their up-selling techniques and skills. Monthly progress reports for each employee, along with guidance on how to achieve their targets, are being received by the hotel.

- Cross-training sessions are held for employees in order to improve their skill set.

- An in-house library was set up for all employees with access to more than 100 books and CDs to improve their personal and professional development.

Table 2: Workforce Development — Learning and Development

\section{Workforce Development — Employee Engagement Initiatives}

Employee involvement, feedback and engagement were sought by the use of three simple "cards":

- "You Deserve It" - to appreciate a colleague and nominate them for the employee of the month award.

- "Hear My Voice" — to provide any kind of feedback to the management.

- "No Idea is Small" - to provide suggestions for improvements aligned with the hotel's values.

Regular staff outings and social activities commenced. Picnics and barbeques are being held along with day visits to popular sites across the UAE, such as Global Village, Heritage Village, Yas Water World and Al Ain Zoo.

A corporate wellness programme has been instituted with monthly medical camps, health check-ups, yoga and other fitness classes and short courses ranging from how to protect yourself from the heat in the summer to how to stay positive and be happy at work and in life.

A quarterly "Grand Breakfast" is hosted where the senior management team cooks and serves breakfast to all employees.

Table 3: Workforce Development — Employee Engagement Initiatives 


\section{Improvements in Communication within the Hotel}

- Monthly town hall meetings were held, many of which were IIP-themed to build awareness and reinforce the messaging.

- An IIP-themed quiz was held to test employee knowledge and understanding of what changes and improvements have been made since the adoption of the IIP framework.

- Regular email updates are sent to all departments regarding any upcoming events and which departments will be involved.

- Revenue and performance data and forward business plans are shared with all departments every quarter to improve inter-departmental and employee awareness.

- Monthly newsletters were started with content contributions from various department heads and employees.

- All employee accomplishments and any important hotel information is put up on the staff notice boards - photographs and images are heavily used to ensure the message reaches all levels of employees.

- An employee Facebook group page (closed group) has been set up where all events and celebrations from the past year, and ongoing, are posted along with the uploads of photographs and videos.

Table 4: Improvements in Communication Within the Hotel

In sum, therefore, focusing on their people development and communication, along with strong management support, enabled the hotel to successfully transform its workplace culture and social climate to one that supported trust, co-operation and employee engagement. As the hotel started demonstrating that they were committed to 'investing in their people', the employees attitudes and behaviours improved and the shift in culture began. Greater inter-department co-operation was observed with teams proactively assisting each other. Employee commitment levels increased as evidenced by people electing to attend optional training courses even on their days off. Staff turnover improved and employee satisfaction surveys were yielding better results as were the customer satisfaction surveys.

In an effort to bring some 'measurement' data to such achievements the benefits to the Hotel can be summarized within two main categories: non-financial and financial. All the financial data presented below has been provided by the case-study hotel during the interviews and as part of the documentary evidence.

\section{Non-financial benefits}

1. Clear organizational direction: With the introduction of the hotel's mission, vision, values and redesigned job objectives, the workforce now has a robust understanding of who they are, where they want to be and how to get there.

2. Improved understanding of own capabilities and ability to shape the future: Upon the insistence of the IIP assessor, the hotel focused their efforts to understand how to quantify and measure the value obtained from various activities that were previously being performed without any form of measurement. This has helped the hotel better understand their operations and produce meaningful data. This data now serves as the baseline to help the hotel structure their work appropriately, build business plans and budget for the future. 
3. Positive workplace culture: There is a culture of trust, transparency and co-operation. Two-way communication is welcomed and encouraged. Employees are engaged and committed since they are made to feel valued, empowered and confident. The hotel quantifies this by linking it to the employee turnover rate which dropped from $35 \%$ in 2014 to only $11 \%$ in 2015 .

4. Skilled Workforce: Due to the enhanced training and development initiatives undertaken, employees are better skilled to do their own jobs and are encouraged to cross-train and develop themselves further. A total of 20 employees were cross-trained in 2015 resulting in 11 internal promotions and 7 transfers. The focus on developing managerial skills and the effective succession planning helps the hotel build its workforce capabilities.

5. Guest satisfaction: The hotel's rating on the popular travel website, TripAdvisor, increased from 4.2 in 2014 to 4.4 in 2015. The Customer Satisfaction Survey results show an increase from $83.6 \%$ in 2014 to $92.1 \%$ in 2015 - against a target of $92 \%$. The Market Metrix scores show an improvement of guest satisfaction scores across all departments of the hotel. (Market Metrix is a third-party vendor that was contracted by the hotel to run their online customer satisfaction surveys).

6. Enhanced reputation/image: Because of being IIP accredited, the hotel witnessed increased media coverage and publicity. The Director of PR and Marketing confirmed that the hotel received several enquiries from competitor hotels wanting to know more about the IIP Standard. Further, the hotel perceives that this accreditation has also established them as a preferred employer.

\section{Financial Benefits}

1. Reduced recruitment cost: Due to reduction in employee turnover, the hotel's recruitment costs have reduced by almost 40\% in 2015 vis-à-vis 2014.

2. Reduced Food \& Beverage cost: The hotel credits training and raising staff awareness on how to optimize food and beverage handling. This has resulted in a $1 \%$ reduction in F\&B costs.

3. Reduced waste disposal cost: Because of training on waste reduction and optimization of resources, the hotel's waste production decreased by 45,000 kilograms in 2015 compared to 2014. The hotel contracts and pays a third-party removal company for their services and due to the reduction in waste produced, the waste disposal costs, in turn, reduced by $32 \%$ in 2015 .

4. Reduced housekeeping/amenities cost: Greater staff awareness resulted in an $11 \%$ reduction in the cost of amenities by the housekeeping department.

5. Increased revenue from restaurant upselling: Revenues from restaurant upselling increased by $16 \%$ in 2015 due to the focus on upselling training techniques.

6. Increased revenue from front office upselling: Revenues from the front office upselling increased in 2015 thereby contributing to a $3 \%$ uplift in overall room revenue.

7. Return on Training: The hotel contracts a third-party training company to work with employees on improving their upselling skills. The hotel has chosen to calculate their 
Return on Training by deducting the amount paid to the training company from the revenues earned on room and F\&B upselling. This has yielded an 86\% return on training in 2015.

Having gone through the IIP journey, the hotel management are strongly of the view that the development taken to move from BE to IIP is something they would strongly recommend to other organizations. They view IIP as the "wake-up call" they needed to bring about significant improvements within the organization. In the case of the financial benefits it is of interest to note that during the interviews it was learned that the hotel did not expect to see any financial returns from the adoption of the IIP Standard at this point. Hence, when they understood how to measure and quantify their activities, it further motivated them to perform better. The cost-save data were shared with the respective departments and the success was celebrated.

It is evident that many of the findings as regards benefits resonate well with the wider research and literature. The non-financial benefits identified here are similar to those noted, for example by Bourne et al., (2008), Cox et al. (2012) and Winterbotham et al. (2013). The results achieved here, described by the hotel management themselves as indirect financial benefits, sit comfortably with what has been found elsewhere, for example, Tamkin, et al., 2008 and Bourne and FrancoSantos, 2010.

\section{Conclusions}

This article aimed to take stock of the practices that can benefit an organization in continuing a journey of improvements to people management and development, beyond BE, by the adoption of IIP. As stated in Part I, the links between BE and IIP are strongest around the practices for people management. This case-study hotel used the BEM model as a starting point and then focused heavily on IIP, primarily developing their workforce, to bring about positive changes in the organizational culture. This, in turn had a knock-on effect of improving organization performance. The case study provides strong testimony that development of a standard beyond $\mathrm{BE}$, and utilizing IIP to take such steps, can bring real benefits to an organization. Importantly, these benefits are not a mere aggregation of IIP and BEM - it is more about finding ways for the models to work together.

Discussion about adopting such an integrated model are evident at a national level within the UAE. In $2011^{1}$ the Department of Economic Development (the custodian of Dubai Quality Award) hosted an introductory seminar about linking IIP to DQA, targeted to private sector organizations. In addition, Dubai Government Excellence Program, recently held a forum around the same concept. The forum ${ }^{2}$ was held in January 2017, attended by 400 government officials representing 30 government agencies from Dubai. It is expected that towards end of 2017 an approach will be developed for the government sector to bring a People Excellence Model that brings together BEM and IIP. ${ }^{3}$

The prospect of an integrated model offers HRD practitioners a challenging but exciting prospect. The BEM model can effectively address the holistic context of organizational development and IIP can address the heart of organization, i.e. its people. For practitioners, the results of this study indicate that adopting an approach that combines BE and IIP has the potential to yield benefits to the organizations such as saving time during the gap analysis and awareness, saving costs, eliminating any perceived duplication, especially along the 'people' dimension where the requirement or bar is set higher in IIP. 
Lessons learned from the case study hotel reveal that to successfully achieve organization's ambition, it is important to consider a phased implementation strategy, one that combines both standards instead of implementing them one after another. It would be prudent to identify which stakeholders should be engaged first (i.e. those who will influence business results the most) and focus on them early in the implementation stage.

Practitioners are also cautioned that in deciding to embark on such an 'organization development' journey they ensure that they have the sponsorship and personal involvement of senior management to maintain the drive and commitment that is required for successful implementation.

It is further suggested that practitioners who are considering pursuing BE and IIP accreditation be mindful of the fact that achieving the accreditation should not be viewed as the aim. The accreditation in itself is only valid for three years after which the organization will be re-assessed should they choose to renew it. Hence, the adoption of these standards should, instead, be viewed as an ongoing learning and improvement journey.

\section{Notes}

1 http://www.smeadvisor.com/news/ded-hosts-first-seminar-on-investing-in-people/

$2 \mathrm{http} / / /$ www.emaratalyoum.com/local-section/other/2017-01-27-1.965101 (in Arabic)

3 https://www.youtube.com/watch?v=eHNH2XFF-fs (in Arabic)

\section{References}

Berry, C., and Grieves, J. (2003). To change the way we do things is more important than the certificate on the wall: does Investors in People represent an effective intervention strategy for organisational learning? The Learning Organization, 10(5): 294-304.

Bourne, M., and Franco-Santos, M. (2010). Investors In People, Managerial Capabilities and Performance. Cranfield: Cranfield University.

Bourne, M., Franco-Santos, M., Pavlov, A., Lucianetti, L., Martinez, V., and Mura, M. (2008). The Impact of Investors in People on People Management Practices and Firm Performance. Centre for Business Performance, Cranfield School of Management, Cranfield.

Collins L. A., and Smith, A. J. (2004). Understanding the new Investors in People standard - lessons from experience, Personnel Review, 33 (5): 583-604

Cox, A., Higgins, T., Tamkin, P., and Ni Luanaigh, A. (2012). Evaluation of Investors in People: employer case studies, Evidence Report 59, UK Commission for Employment and Skills, London.

European Foundation for Quality Management (EFQM) (2003). The EFQM Model, EFQM, Brussels, Belgium.

Garad, A. (2016). Investors in People and Business Excellence in the United Arab Emirates Part 1: Establishing the Link, International Journal of HRD Practice, Policy and Research, 1(2): 83-92.

Hill, R., and Stewart, J. (1999). Investors in People in small organizations: learning to stay the course?, Journal of European Industrial Training, 23(6): 286-299.

Smith, A. J., Boocock, G., Loan-Clarke, J., and Whittaker, J. (2002) IIP and SMEs: awareness, benefits and barriers, Personnel Review, 31 (1): 62-85

Smith, P. J. (2000). Implementing Investors in People: a case study from the NHS, Journal of European Industrial Training, 24 (5): 275-280.

Tamkin, P., Cowling, M., and Hunt, W. (2008). People and the Bottom Line (Report No. 448) Brighton: Institute for Employment Studies.

Winterbotham, M., Huckle, C., James, A. S., and Jones, R. (2013). Research to support the evaluation of Investors in People: employer survey (Year 2)', Evidence Report 68, UK Commission for Employment and Skills, London. 


\section{The Authors}

In addition to his engagement with Investors in People UAE, Alaa Garad works as an Assistant Professor at Abu Dhabi University. He holds a Bachelor of Commerce, a Master's Degree in Quality Management and a $\mathrm{PhD}$ in Organizational Learning. Alaa is an Accredited EFQM Assessor, IIP Specialist, Chief Examiner and Juror for several national and regional quality awards such as Sheikh Khalifa Excellence Award, Dubai Quality Award, and King AbdulAziz Quality Award in Saudi Arabia. He is a member of the Academy of Management, and the American Society for Quality and a Founding member of the Egyptian Association for Learning.

Fiona Martis is a Dubai-based management professional with over 20 years of practice in the UAE's banking and finance sector. Her areas of expertise include customer experience management, consumer insights and advocacy, change management and training and talent development. Through her MBA from Middlesex University, she concentrated on business excellence and organizational learning to further explore the relationship between effective talent development and positive business performance. She may be contacted at www.linkedin. com/in/fionamartis for any queries. 